\title{
PROFESSOR DE EDUCAÇÃO FÍSICA NO ENSINO FUNDAMENTAL: SABERES, CONCEPÇÕES E SUA PRÁTICA DOCENTE
}

\section{Cláudia Renata Rodrigues Xavier}

Universidade Federal do Mato grosso do Sul, Campo Grande, Mato Grosso do Sul, Brasil

\begin{abstract}
Resumo
O objetivo deste artigo é apresentar os resultados da pesquisa "Professor de Educação Física no Ensino Fundamental: Saberes, Concepções e sua Prática Docente”. O universo pesquisado foi composto por 10 professores de Educação Física que atuam nos anos iniciais do Ensino Fundamental na REME/Campo Grande-MS, exercendo a docência num tempo entre cinco a oito anos. Utilizamos os pressupostos da abordagem qualitativa no desenvolvimento da pesquisa e, para o levantamento dos dados, a entrevista semiestruturada e a análise de documentos. Um dos resultados obtidos foi o de que há uma preocupação constante dos Professores em relação à sua formação continuada, eles querem se atualizar, estudar, frequentar palestras, cursos e encontros.
\end{abstract}

Palavras chave: Professor de Educação Física. Ensino Fundamental. Saberes Docentes

\section{Introdução}

Os estudos sobre a profissão docente evidenciam que o professor, como profissional ao longo da história, teve várias denominações, como: detentor do saber, mestre, herói, e, ao mesmo tempo, é considerado como um dos responsáveis pelos problemas educacionais. Outro ponto a ser destacado diz respeito à formação de professores que, ao longo do tempo, passou por transformações com o intuito de atender a diferentes concepções e leis no decorrer da história da educação.

Alguns autores da área educacional sinalizam a postura que o docente deve ter para ensinar. Assim, apontam para o professor como mediador, como sujeito em constante aperfeiçoamento profissional, no que se refere ao processo de ensino-aprendizagem. Além disso, o professor deve adotar uma postura que o faça rever suas experiências, criando subsídios para 
estabelecer uma relação mais afetiva com o aluno, a fim de que ambos aprendam juntos no decorrer do processo educativo. (NÓVOA, 2000; MIZUKAMI, 1996; PIMENTA, 1999).

Diante do exposto, nos últimos anos pesquisadores nos alertam para a dificuldade de se materializar os avanços teóricos ocorridos na área da Educação Física Escolar brasileira (CAPARROZ e BRACHT, 2007, SANTOS et al, 2009). Esse fato ocorre principalmente pela atribuição ao professor de único responsável por tal dificuldade, o que desconsidera muitos fatores, como por exemplo, condições de trabalho, bem como os profissionais que dificultam ações para o desenvolvimento de práticas emancipatórias e reflexivas.

Não concordamos com tal compreensão que culpa o professor e que também the atribui a ideia daquele que somente "joga bola"[1], pois acreditamos que o profissional de Educação Física contribui para a apropriação, por parte dos alunos, de conhecimentos que lhes possibilitam uma leitura mais crítica do mundo no qual estão inseridos.

Temos a certeza também que a prática docente do profissional de Educação Física, com ênfase apenas no esporte, habilidades motoras ou capacidades físicas, como é desenvolvida por alguns desses professores na escola, hoje deve ser repensada e ressignificada, pois somente esses focos não são suficientes para a formação do aluno, com vistas à sua atuação na sociedade. Por exemplo, não basta apenas o aluno aprender a técnica do esporte, mas é necessário compreender suas regras, respeitar o colega, jogando com ele e não contra.

O professor de Educação Física tem à sua disposição um leque de saberes que podem/devem ser utilizados em sua prática pedagógica e com seus alunos por meio da ludicidade, das brincadeiras, dos jogos, da dança, da ginástica, entre outros, proporcionando-lhes o despertar para a importância da afetividade, do respeito ao próximo, às regras e normas, assim como instigar o desenvolvimento do seu senso crítico, permitindo aos mesmos uma maior compreensão do mundo em que vivem e como se estabelecem as relações com o outro.

É fato, também, que esse profissional, no decorrer de sua carreira, passa por várias transformações em sua vida pessoal e profissional, as quais vão delineando sua constituição como professor, além de contribuir para a (re)significação de conceitos, saberes e prática.

Neste sentido, realizamos uma pesquisa no ano de 2009, intitulada "Professor de Educação Física no Ensino Fundamental: Saberes, Concepções e sua Prática Docente", que teve como objetivos: identificar os saberes e as concepções de ensino e aprendizagem que perpassam a prática dos professores de Educação Física dos anos iniciais do Ensino Fundamental (que

Pensar a Prática, Goiânia, v. 17, n. 2, p. 345-358, jan./mar. 2014 346 
já exercem a docência por um período que consideramos definidor de sua opção pela mesma, compreendido entre cinco e oito anos); bem como conhecer o significado da docência.

Assim, no presente artigo apresentaremos os resultados da pesquisa sobre a visão dos professores de Educação Física deste estudo. E para discutirmos os resultados sintetizamos algumas categorias que foram apresentadas no decorrer da pesquisa: conhecimento amplo; trabalho com demais disciplinas; gostar da profissão; dificuldades; número elevado de aulas; infraestrutura inadequada; ecletismo; Crítica-Emancipatória; e Crítica-Superadora.

Neste estudo nos embasamos em autores como Freire (1989), Huberman (2000), Gauthier (1998), Tardif (2002/2005), Shigunov et. al (2002), Kunz (2003), Gariglio (2006), Soares et al, (1992); Bracht (1997); Betti, (2005); Galvão et al, (2005), Moreira (2006), Santos et al (2009), para melhor compreendermos os saberes, concepções e a prática docente dos sujeitos da pesquisa.

\section{Metodologia}

Neste estudo seguimos os passos da abordagem qualitativa e como instrumentos de levantamento de dados foram realizadas duas entrevistas com roteiro semi-estruturado construído pela pesquisadora e sua orientadora, e análise de documentos e legislações oficiais. Realizamos a pesquisa de campo no ano de 2009, com 10 professores de Educação Física que atuam nos anos iniciais do Ensino Fundamental da Rede Municipal de Ensino (REME) de Campo Grande-MS, os quais exercem a docência num tempo compreendido entre cinco e oito anos.

A escolha do tempo de docência fundamentou-se nos estudos realizados sobre "Os ciclos de desenvolvimento profissional" de Huberman (2000 p.47), que resume o percurso do ciclo de vida profissional do docente em anos e fases da carreira: "[...] 1-3 anos (Entrada); 4-6 anos (Estabilização ou Consolidação); 7-25 anos (Diversificação), 25-35 (Serenidade) e 35-40 anos (Desinvestimento)".

Assim, para chegarmos a essa escolha, contatamos 355 professores de Educação Física e, desse total, 232 atuavam nos anos iniciais do Ensino Fundamental. Desse quantitativo, 33 tinham o tempo definido por nós como critério para o desenvolvimento da pesquisa.

A investigação foi por amostragem: escolhemos dez professores que atendiam aos seguintes critérios: (a) - serem professores de Educação Física com atuação entre cinco e oito anos de docência; (b) - professores do Ensino Fundamental. A escolha dos professores foi aleatória entre aqueles que preenchiam nossos critérios. Assim, chegamos a três professores com oito,

Pensar a Prática, Goiânia, v. 17, n. 2, p. 345-358, jan./mar. 2014 347 
sete, seis e cinco anos de docência, respectivamente. Portanto, os sujeitos do estudo aparecem da seguinte forma: Professor 1, Professor 2, e assim sucessivamente.

Após o trâmite legal, conversamos com os professores participantes da pesquisa e explicamos como seria a participação deles na mesma. Após a aceitação, assinaram um Termo de Consentimento Livre e Esclarecido, para, então, efetivarmos a realização das entrevistas.

$\mathrm{Na}$ investigação, após o período de leitura e releitura das informações recolhidas de textos produzidos por autores que discutem sobre os saberes docentes, agrupamos as falas dos sujeitos por semelhanças e diferenças, e destacamos os elementos considerados significativos que permitiram uma melhor compreensão das respostas dos professores de Educação Física que trabalham nos anos iniciais do Ensino Fundamental. Ressaltamos que as entrevistas semiestruturadas foram transcritas fidedignamente conforme a fala de cada professor.

\section{Discussão e Resultados}

Há uma infinidade de saberes, e não somente aqueles sistematizados nas Instituições de Ensino Superior e na escola, mas também aqueles que se constituem na sociedade de forma geral, no dia a dia, na vida das pessoas. Reafirmando essa ideia, Tardif (2005), ao referir-se ao início da carreira docente, assinala que os professores utilizam:

[...] constantemente seus conhecimentos pessoais e um saber-fazer personalizado, trabalham com programas e livros didáticos. Baseiam-se em saberes escolares relativos às matérias ensinadas, fiam-se em suas experiências e retêm certos elementos de sua formação profissional. (TARDIF, 2005, p.64).

E isto o docente faz no início da carreira sem ter ideia de onde vêm alguns dos saberes aprendidos ou quem os elaborou, e mesmo sem questioná-los, os reproduz naturalmente. A esse respeito, Santos et. al (2009) alerta para que não sejam privilegiados os saberes acadêmicos, em detrimento daqueles que os professores trazem de suas histórias de vida na escola, na família, entre outros.

As ideias de alguns autores como SOARES et. al (1992), BRACHT (1997), BETTI (2005) e GALVÃO et al (2005) se identificam quanto aos saberes específicos da Educação Física, os quais fazem parte da cultura corporal de movimento: a dança, o jogo, o esporte, a ginástica e a luta. Estes sa- 
beres devem ser apropriados pelo professor para serem ensinados na escola numa perspectiva crítica, ao invés de o mesmo somente preocupar-se em desenvolver nos seus alunos habilidades e técnicas desportivas.

Referendando a prática pedagógica, Huberman (2000) nos mostra que é durante o transcorrer da carreira docente que podem ocorrer transformações significativas na vida profissional, acarretando em decisões importantíssimas sobre como continuar ou não na carreira.

Assim, o saber da experiência na docência entre cinco e oito anos de profissão (fase de estabilização e diversificação para Huberman (2000), adotada neste estudo) possibilita ao professor de Ed. Física atuar na escola compromissado com a carreira, nos investimentos que faz, na formação continuada, na serenidade com que enfrenta as situações inesperadas.

Dessa forma, perguntamos para os professores: Quais conhecimentos vocês consideram importantes de se apropriar para desenvolver uma prática pedagógica que atenda aos interesses dos alunos?

Para os Professores 3 e 10, os conhecimentos que consideram mais importantes em suas práticas pedagógicas são a proximidade com os alunos, a confiança que os mesmos têm em relação a eles e o fato de a especificidade da sua disciplina permitir que trabalhem em suas aulas conhecimentos mais gerais. Os mesmos professores expressam em suas falas:

[...] o professor de Educação Física tem que ter um conhecimento geral de tudo quanto é assunto para poder ter esse contato com ele para chegar conversar e, colocar as coisas para ele sem ser muito autoritário." (Professor - 3) . "Deve ser geral para que o aluno possa ter um conhecimento, um acesso aprendizagem geral, não ficar somente restrito, a um determinado conteúdo. Ser um pouquinho de cada matéria ser passado para eles. (Professor -10).

Os Professores acima se referem ao trabalho com as demais disciplinas do currículo, e ao conhecimento amplo. Isso demonstra que os saberes que ambos enunciaram são os disciplinares, que, segundo Gauthier (1998) e Tardif (2002), são os saberes produzidos tanto por cientistas como por pesquisadores na mais variadas disciplinas. E os professores têm como referência a especificidade de cada disciplina que deve ser respeitada e considerada em suas práticas docentes.

Os Professores 1, 4, 8 e 10, quando se reportam ao conhecimento necessário para preparar suas aulas, apresentam especificidades da fase de estabilização, as quais, segundo Huberman (2000, p. 40- grifo do autor), "[...] evocam características que remetem a sentimentos de confiança e de "conforto".

Pensar a Prática, Goiânia, v. 17, n. 2, p. 345-358, jan./mar. 2014 349 
Outra questão relevante que nos revela quais saberes os professores de Educação Física que atuam entre cinco e oito anos na REME mobilizam para o exercício da docência, é a questão do ensino, pois, ao nos relatarem sua compreensão sobre ensinar, estes professores nos apresentam sua visão de aluno e aprendizagem. E perguntamos a nossos sujeitos: O que representa ensinar Educação Física?

As respostas deles foram mescladas, superficiais e revelaram pouco conhecimento teórico. Destacamos alguns recortes das falas que confirmam a nossa ideia: "ensinar Educação física é conhecer o aluno como ele é", "o aluno é uma pessoinha", "ensinar é uma dádiva", "ensinar Educação física é ensinar a viver em sociedade". Tais constatações estão explícitas nas falas que seguem:

[...] acho que ensinar Educação Física na verdade é um prazer, porque você vê o tanto de alegria que você pode promover a uma criança. (Professor 1)

[...] Eu acho que antes de tudo tem que ter amor e gostar do que faz, para daí você conseguir um bom trabalho. Eu acho que a Educação Física é uma matéria muito, muito especial. A gente tem um contato muito próximo com a criança. (Professor 2)

Ensinar Educação Física é ensinar respeito, ensinar coletividade, é ensinar regras, tudo isso está baseado dentro do que a Educação Física oferece nas aulas. . (Professor 3)

[...] ensinar Educação Física é conhecer o aluno realmente como ele é. Pra mim é isso. (Professor 7)

[...] Ensinar a Educação Física significa levar a criança a superar as suas dificuldades, uma criança que no começo do ano nem fala, nem responde a chamada e passa a interagir com o grupo. . (Professor 9)

Ao analisar as falas também observamos que, segundo o Professor 1, ensinar a disciplina da Educação Física proporciona muito prazer, em razão de ele poder promover a alegria, como também, reconhecer o valor que o aluno tem. Para o Professor 7, ensinar significa conhecer o aluno como ele é. A docência, para ele, acontece por meio do contato afetivo com o aluno. Fato que se assemelha com a resposta do Professor 2, para quem ensinar, 
primeiramente, é ter amor e gostar da profissão. Este reconhece a Educação

Física como uma matéria especial, que proporciona contato muito próximo com o aluno.

Para o Professor 9, ensinar significa levar a criança a superar suas dificuldades, interagindo com o grupo, aprendendo com os colegas, ajudar no seu desenvolvimento. O Professor 3 acredita que ensinar a Educação Física é ensinar o respeito, a coletividade, as regras, o trabalho em grupo, dupla e trios por meio do jogo.

Esse contato mais próximo com o aluno a que se referem os Professores 7 e 2 nos faz retomar o pensamento de Moreira (2006, p. 30), quando este salienta que faz-se necessário que "[...] o professor estabeleça uma relação de parceria com suas turmas, mas para isso deverá analisar o contexto em que estão inseridos diagnosticando as reais necessidades do grupo de aluno". Fato que acreditamos ser importante, pois, dessa forma, o professor de Educação Física tem mais chances de acertar em suas decisões, principalmente as relacionadas ao seu planejamento e ao trabalho com os conteúdos de ensino.

Observamos também certa semelhança com relação à concepção de ensino expressa nas falas dos Professores 1, 2, 3, 7 e 9, com o que está proposto no Referencial Curricular $1^{\circ}$ e $2^{\circ}$ anos da REME - quando este se refere à abordagem histórico-cultural ou sócio-histórica, enfatizando a interação entre as pessoas e a relação com o meio cultural no qual se efetivam o ensino e a aprendizagem.

A noção de carreira tem se empregado nos últimos anos como uma maneira de entender a evolução profissional dos professores. Assim, no exercício da docência aparecem diversas transformações que podem ser significativas na vida profissional dos mesmos. Essas transformações nem sempre são positivas e nem acontecem da mesma forma para todos. Às vezes, o professor encontra obstáculos que o impossibilitam de realizar uma prática diferenciada, o que acaba desestimulando-o e fazendo com que ele "estacione" na carreira. Outras vezes, ele se sente mais motivado com o seu trabalho, o que pode ajudar no crescimento profissional.

Para entendermos melhor essas transformações nos reportamos aos estudos desenvolvidos por Huberman (2000), que resume o percurso do ciclo de vida profissional do docente em anos e fases da carreira.

Foi possível encontrarmos nesse estudo as classificações das fases da carreira de Huberman (2000), quando perguntamos para os professores se eles, no momento atual, se sentem motivados e mais comprometidos com a profissão, e solicitamos que dissessem o porquê. As respostas semelhantes foram:

Pensar a Prática, Goiânia, v. 17, n. 2, p. 345-358, jan./mar. 2014 351 
É, eu não diria mais motivado, que também no início você sai com todo gás, com toda motivação, e aí às vezes vem aquele balde de água fria que não é bem aquilo que você esperava. [...] Então me sinto motivado pelo fato de eu gostar. (Professor 1)

Eu estou sim. No começo me deu uma frustração porque a gente sai da universidade achando que vai encontrar uma coisa e na realidade entra outra bem diferente. Não era aquilo que a gente tinha nas aulas de prática de ensino e de pedagogia, porque a gente dava aula para alunos de escolas ou para os próprios colegas em pouco espaço de tempo, tudo parecia mais fácil. [...] A minha motivação partiu de saber que hoje vou para a escola e sei o que vou encontrar. (Professor 4)

Identificamos que ambos os professores sentiram dificuldades no início da carreira, a qual é denominada por Huberman (2002, p. 39 - grifo do autor) de "[...] "sobrevivência" e traduz o que chama vulgarmente o "choque do real". O que significa o confronto da formação acadêmica nas Instituições de Ensino Superior com a realidade encontrada nas escolas das diferentes redes de ensino.

A frustração comentada pelo Professor 4 remete às dificuldades, como: o número elevado de alunos, uma quantidade maior de horas-aula, infraestrutura inadequada etc. O Professor 1 disse ter saído com todo "gás" da graduação, e ter recebido um "balde de água fria". Nessa fala, podemos inferir que ele se refere às mesmas dificuldades encontradas na escola.

Outro aspecto importante que ambos os professores apresentam é que mesmo que eles tenham vivenciado, no início de carreira, situações muitas vezes desconfortáveis, hoje, na fase em que se encontram (a estabilização), confirmam o que Huberman (2002) define como mais seguros, com certa independência no agir pedagógico e até mesmo mais comprometimento com a profissão.

Além dos princípios teóricos, perguntamos também aos professores com quais desses conhecimentos eles se identificavam. Suas respostas variaram, e mais uma vez eles deixaram clara a falta de conhecimento teórico e, por conseguinte, uma insegurança em relação ao preparo das aulas e aos seus objetivos ao escolher esta ou aquela atividade ou exercício.

Sintetizamos as falas do Professor 1, que diz se identificar com a "Desenvolvimentista, Crítico-Emancipatória, Crítico-Superadora." Os Professores 2 e 6, com a "Desenvolvimentista e a Construtivista", como também o Professor 4. Os Professores 3, 7, 8 e 9 com a "Crítico-Emancipató- 
ria", e o Professor 10 diz não se prender a nenhuma linha: "Tento relacionar várias teorias com a prática." $\mathrm{Na}$ resposta, este tentou explicar com qual abordagem se identifica, mas não deixou claro. Apenas afirmou que se preocupa mais com sua prática, sem descartar a teoria.

Ao reler as falas dos professores, percebemos que eles não têm uma ideia clara sobre as concepções em que se apoiam, visto que suas respostas se contrapõem às das abordagens Desenvolvimentistas, que se preocupam apenas com o desenvolvimento físico e o aspecto motor (TANI, et al, 1988), e também da Construtivista, que enfatiza o conhecimento construído por meio da interação do sujeito com o mundo (FREIRE, 1989). Essas abordagens não fazem parte das críticas, pois seus enfoques se diferenciam, são abordagens apenas psicológicas e motoras. Por esse motivo, não as aprofundamos nesse estudo.

Os professores disseram que desenvolvem seu trabalho calcados nas abordagens Crítico-Emancipatória e Crítico-Superadora. A abordagem Crítico-Superadora a que se refere o Professor 1 surgiu por volta de 1992, influenciada pela concepção histórico-crítica desenvolvida por Saviani e colaboradores, e tem suas bases filosóficas fundamentadas no marxismo, que busca, por meio de suas reflexões, a superação dos ditames do capitalismo. A prática pedagógica do professor de Educação Física que segue esta abordagem tem por características: ser diagnóstica e remeter à constatação e à leitura dos dados da realidade (SOARES, et al 1992).

Já a abordagem Crítico-Emancipatória citada pelos Professores 3, 7, 8 e 9 é inspirada nos pressupostos da Teoria Crítica de Escola de Frankfurt, que também tem suas bases filosóficas fundamentadas no marxismo. Um dos seus representantes é Jürgen Habermas, que tem sua teoria seguida por Dr. Elenor Kunz na Educação Física.

A abordagem Crítico-Emancipatória prima pela compreensão crítica do mundo, da sociedade e de suas relações, coloca o aluno em confronto com a realidade, propondo o questionamento e a libertação de condições limitantes e repressoras da sociedade. Isto se dará por meio do ensino da cultura corporal de movimento, como o esporte, o jogo, a dança, etc. (KUNZ, 2003).

Após discorrermos sobre algumas falas que retratam a visão dos professores de Educação Física que atuam na docência no Ensino Fundamental, num período compreendido entre cinco e oito anos, e que se encontram nas fases de estabilização e diversificação, apresentamos resultados pontuais levantados durante a pesquisa:

- Há uma preocupação constante dos professores em relação à sua formação continuada; Eles querem se atualizar, estudar, frequentar palestras, cursos e encontros.

Pensar a Prática, Goiânia, v. 17, n. 2, p. 345-358, jan./mar. 2014 353 
- A atualização, durante o exercício da docência, é fundamental para o professor de Educação Física em sua carreira, pois torna necessário que o mesmo saiba aproveitar os conhecimentos oferecidos, a fim de ter criticidade para filtrar o que é relevante ou não para a sua prática pedagógica.

- Os sujeitos de nosso estudo veem como fatores positivos na sua profissão o prazer em ensinar, a troca de experiências com os alunos, a interação entre aluno e professor e a estabilidade no emprego.

- Os professores reconhecem como aspectos negativos da profissão os fatores sociais em todas as suas dimensões, especialmente: a falta de respeito dos alunos para com seus professores, o não reconhecimento de sua profissão por parte dos colegas e até mesmo dos alunos, as precárias condições de trabalho, entre outros que emergem no cotidiano escolar.

- Os professores de Educação Física que atuam nos anos iniciais do Ensino Fundamental e que se encontram em um estágio mais avançado da carreira (entre cinco e oito anos), na construção de sua carreira profissional, se pautam em princípios e abordagens como a Crítica-Superadora, a CríticaEmancipatória e a Desenvolvimentista, o que mostra que o ecletismo faz parte das práticas desses professores.

- Os professores de Educação Física que participaram de nosso estudo mobilizam em suas práticas os saberes profissionais, disciplinares, curriculares e experienciais, além dos específicos da cultura corporal de movimento (o jogo, a dança, o esporte, a ginástica e as lutas), sem se dar conta de que todos subsidiam suas práticas.

- É necessário que o professor se conscientize e reflita que existem inúmeras estratégias de ensino críticas e emancipatórias, ou mesmo atitudes (como o diálogo) nas relações com os alunos que podem eliminar atitudes tradicionais.

- Durante suas aulas, os professores de Educação Física devem atuar com vistas à emancipação (tanto a própria como a de seus alunos), superando as limitações que podem emergir no dia a dia e nas relações com os colegas.

- As práticas dos professores que participarem deste estudo se apoiam em princípios e abordagens críticas e tradicionais, e dão ênfase ao desenvolvimento das potencialidades do aluno por meio da cultura corporal de movimento, sem supervalorizar o esporte.

- Os professores estudados concebem o ensino e a aprendizagem articulando-os com o contexto sócio histórico em que os alunos se inserem.

- Tais professores recorrem a práticas pedagógicas interativas e ao mesmo tempo tradicionais.

- O referencial curricular da REME baseia-se em princípios críticos para a Educação Física e determina que sua prática deve conter os aspectos

Pensar a Prática, Goiânia, v. 17, n. 2, p. 345-358, jan./mar. 2014 354 
cognitivo, social e afetivo, além de aspectos da cultura corporal de movimento.

- Os documentos dos PCNs de Educação Física e o Referencial Curricular para o Ensino Fundamental $-1^{\circ}$ e $2^{\circ}$ anos, em seus textos, não apresentam soluções efetivas para resolver os problemas do cotidiano escolar, mas mostram medidas para amenizar situações, como adaptação das aulas a outros espaços - jardim, campinho, pátio, ou mesmo fora da escola, como em reservas florestais, academias etc.

- Esta pesquisa também nos mostra que a constituição do professor de Educação Física e sua profissionalidade são construídas em espaços escolares e não escolares desde o início de seus estudos na Educação Básica e na universidade, bem como desde o início da carreira docente.

- A Educação Física é um componente curricular obrigatório que deve fazer parte da Educação Básica da escola.

\section{Considerações Finais}

O professor, no decorrer de sua prática docente, constrói gradativamente sua carreira profissional, por meio de experiências familiares, profissionais, escolares etc., e aprende com elas a ser professor e a desenvolver competências para ensinar. Após a sua formação inicial, o processo da construção da docência continua por meio da interação na escola com seus alunos, colegas de trabalho, participando de cursos e aprendendo com diferentes situações de ensino e aprendizagem. Aspectos estes que podem ser entendidos melhor quando estudamos o percurso do ciclo de vida profissional docente em anos e fases (HUBERMAN, 2000).

Os diferentes saberes se ligam ao universo de trabalho do professor de uma forma geral, fazem parte de sua formação docente, na sua forma de ensinar os conteúdos e pelas interações que acontecem na sala de aula e ao longo da sua vida profissional. No caso dos professores de Educação Física dos anos iniciais do Ensino Fundamental, isso se dá por meio da cultura corporal de movimento (o jogo, a dança, entre outros), que são seus saberes específicos. Além desses, o professor deve ter conhecimento de outros saberes e, principalmente, do "saber experiencial".

Por fim, ao concluir este estudo, acreditamos que a mudança de paradigmas leva a uma condição mais crítica sobre o fazer pedagógico do professor de Educação Física. Primeiramente, o professor deve mobilizar o querer fazer pessoal, para que ele possa pensar em práticas emancipatórias que proporcionem mudanças reais na ação docente, bem como, na melhoria da aprendizagem dos alunos no sentido de formar cidadãos mais críticos.

Pensar a Prática, Goiânia, v. 17, n. 2, p. 345-358, jan./mar. 2014 355 
[1] A expressão professor-bola refere-se à ação em que o professor, em uma aula de Educação Física, tem a finalidade apenas de entregar a bola ou outros materiais aos seus alunos.

\title{
PHYSICAL EDUCATION TEACHING IN ELEMENTARY EDUCATION: KNOWLEDGES, CONCEPTS AND THEIR TEACHING PRACTICE
}

\begin{abstract}
The objective of this paper is to present the results of Professor of Physical Education in Elementary Education: Knowledges, Concepts and their Teaching Practice. The research universe consists of 10 physical education teachers which work in the early years of REME elementary schools / Campo Grande-MS, been teaching classes for about five and eight years. To develop this study qualitative research assumptions were used and to survey data, semi-structured interviews and document analysis. One of the results - There is a constant teachers concern regarding their continuing education, desire to upgrade, to study and attend lectures, courses, meetings.
\end{abstract}

Keywords: Physical Education Teacher. Elementary Education. Teachers knowledge

\section{FÍSICA MAESTRO EDUCACIÓN EN EDUCACIÓN PRIMARIA: CONOCIMIENTOS, CONCEPTOS Y PRACTICAR SUS DOCENTE}

\section{Resumen}

El objetivo de este trabajo es presentar los resultados de la investigación el profesor de Educación Física en la Educación Primaria: conocimientos, conceptos y sus prácticas de enseñanza. El universo de la investigación se compone de 10 profesores de educación física que trabajan en los primeros años de escuela primaria en el REME / Campo Grande-MS, el ejercicio de un tiempo de enseñanza entre cinco y ocho años. Los supuestos fueron utilizados en el desarrollo de la investigación cualitativa y los datos de la encuesta, las entrevistas semiestructuradas y análisis de documentos. Uno de los resultados - Hay una preocupación constante de los docentes con respecto a su educación continua, queremos mejorar, estudiar, asistir a conferencias, cursos, reuniones.

Palabras-claves: Profesor de Educación Física. Educación Primaria. Los maestros los conocimientos

\section{Referências}

BRACHT, V.; CAPARROZ, F. E. O tempo e o lugar de uma Didática da Educação Física. Revista Brasileira de Ciências do Esporte, Colégio 
Brasileiro de Ciências do Esporte, Campinas, Autores Associados, v. 28, n. 2, p. 21-37, jan, 2007

BRACHT, V. Educação Física e aprendizagem social. Porto Alegre: Magister, 1997.

BETTI M. Educação Física. In GONZÁLEZ, F. J.; FENSTERSEIFER, P. E. (Org.) Dicionário crítico de Educação Física. Ijuí: Editora Unijuí, p. 144155, 2005 b.

CAMPO GRANDE-MS, Referencial Curricular da Rede Municipal de Ensino $1^{\circ}$ e $2^{\circ}$ ano Ensino Fundamental, vol. I, 2008.

FREIRE, J. B. Educação de corpo inteiro: teoria e prática da Educação Física. São Paulo: $2^{a}$ ed. Scipione, 1989.

GARIGLIO, J. A. Professores de educação física de uma escola profissionalizante e sua cultura docente: as interconexões entre os saberes da base profissional e o campo disciplinar. Pensar a Prática, Goiânia, v. 9, n.2: 249$266 \mathrm{jul} / \mathrm{dez}, 2006$.

GALVÃO, In DARIDO, S.; RANGEL, I. C. A. E - Educação Física na escola: implicações para a prática pedagógica. Rio de janeiro: Guanabara Koogan, 2005.

GAUTHIER, [et al]. Por uma teoria da pedagogia: pesquisas contemporâneas sobre o saber docente. (Coleção fronteiras da educação). Trad. Francisco Pereira - Ijuí: Ed. UNIJUÍ, 457p., 1998.

HUBERMAN, M. O ciclo de Vida profissional dos Professores (Coleção Ciências da Educação). In NÓVOA, António (Org.) Vidas de professores. Porto Editora LTDA: Porto - Portugal, 2a ed., 2000.

MIZUKAMI, M. da G. N.- Ensino: as abordagens do processo. Temas básicos de educação e ensino. São Paulo: EPU, 1986.

MORREIRA, E. C. (Org.) Educação Física Escolar: desafios e propostas, Jundiaí, Fontoura Editora, 2006.

NÓVOA, A. (Org.) Profissão Professor. Coleção Ciências da Educação.Porto-Portugal, PORTO EDITORA 2a ed., 2000.

Pensar a Prática, Goiânia, v. 17, n. 2, p. 345-358, jan./mar. 2014 357 
PIMENTA, S. G. (Org.). Saberes pedagógicos e atividade docente. São Paulo: Cortez,1999.

SANTOS, N. Z dos et al . Vida de Professores de Educação Física: o pessoal e o profissional no exercício da docência. Movimento, Porto Alegre, v. 15, n. 02, p. 141-165, abril/junho de 2009.

SOARES, C. L. et al. Metodologia do ensino da educação física - coletivo de autores. Coleção magistério $2^{\circ}$ grau. Série formação do Professor - Cortez: São Paulo-SP, 1992.

SANTOS, N. Z dos et al . Vida de Professores de Educação Física: o pessoal e o profissional no exercício da docência. Movimento, Porto Alegre, v. 15, n. 02 , p. 141-65, abr/jun de 2009.

SHIGUNOV Neto, A., SHIGUNOV V. (Org.). Educação Física: Conhecimento Teórico x Prática Pedagógica. Porto Alegre, RS: Mediação, 2002.

TARDIF, M. Saberes docentes e formação profissional. Petrópolis: Vozes, 2002.

O Trabalho Docente: elementos para uma teoria da docência como profissão de Interações humanas. Maurice Tardif, Claude Lessard; Trad. de João Batista Kreuch - 2a ed. Petrópolis, RJ: Vozes. 2005.

TANI G. et al. Educação Física Escolar: fundamentos de uma abordagem desenvolvimentista. São Paulo: Editora da Universidade de São Paulo, 1988.

Recebido em: 22/04/2013

Revisado em: 21/10/2013

Aprovado em: 04/12/2013

Endereço para correspondência:

crrx.ms@ hotmail.com

Cláudia Renata Rodrigues Xavier

Prefeitura Municipal de Campo Grande, Secretaira Municipal de Educação.

Rua Onocieto Severo Monteiro no 460

Vila Margarida

79002-949 - Campo Grande, MS - Brasil

Pensar a Prática, Goiânia, v. 17, n. 2, p. 345-358, jan./mar. 2014 358 